\title{
Identification and Characterization of Pestalotiopsis spp. Causing Scab Disease of Guava, Psidium guajava, in Hawaii
}

\author{
Lisa M. Keith, Maile E. Velasquez, and Francis T. Zee, Tropical Plant Genetic Resource Management Unit, Pa- \\ cific Basin Agricultural Research Center, USDA-ARS, Hilo, HI 96720
}

\begin{abstract}
Keith, L. M., Velasquez, M. E., and Zee, F. T. 2006. Identification and characterization of Pestalotiopsis spp. causing scab disease of guava, Psidium guajava, in Hawaii. Plant Dis. 90:16-23.

Guava is one of the most widely grown plants in the tropics; however, it is affected by many fruit rot diseases. Fruit diseases decrease the marketability of fresh fruit and fruit for processing. A survey of scab disease was conducted at the USDA/ARS Tropical Plant Genetic Resource Management Unit in Hilo, HI, where more than 50 accessions of guava are grown. Symptoms observed were gray/light brown lesions surrounded by dark brown borders on leaves and brown, raised, corky, necrotic lesions on the exocarp of fruit which progressed as the fruits matured. Seventeen isolates from infected fruit, six isolates from lesions on leaves, and nine isolates from additional crops surrounding the guava trees were collected. The main fungi consistently isolated from symptomatic leaves and fruit were Pestalotiopsis spp. Morphology, colony characteristics, and pathogenicity of the isolates were examined and potential sources of host resistance were identified for germplasm characterization studies. Molecular methods were used to identify four Pestalotiopsis taxa (P. clavispora, P. microspora, P. sp. GJ-1, and P. disseminata) on guava in Hawaii. To our knowledge, this is the first report of traditional and molecular methods of identification and characterization being used for fungal pathogens of guava in Hawaii.
\end{abstract}

Guava (Psidium guajava L.) is grown in nearly every tropical and frost-free subtropical country in the world. It is grown in soils of various textures, drainage, $\mathrm{pH}$ (ranging from 4.5 to 9.4 ), salinity, and soils both rich and poor in basic cations (18). In addition, guava grows naturally in areas of high mean annual rainfall and can also withstand drought conditions (18). According to Hawaii Agricultural Statistics Service (HASS), guava production utilized for processing totaled 3 million $\mathrm{kg}$ in 2003 , with statewide farm values totaling $\$ 925,000$ (2).

Increased cultivation of guava and the popularity of certain varieties in some regions (e.g., Taiwan) have resulted in an increase in guava diseases, including new fruit rot diseases that cause great losses in production (15). Scabby fruit canker,

Corresponding author: L. M. Keith E-mail: lkeith@pbarc.ars.usda.gov

* The $\boldsymbol{e}$-Xtra logo stands for "electronic extra" and indicates the HTML abstract available on-line contains a supplemental figure not included in the print edition.

Accepted for publication 15 August 2005.

DOI: 10.1094/PD-90-0016

This article is in the public domain and not copyrightable. It may be freely reprinted with customary crediting of the source. The American Phytopathological Society, 2006. caused by Pestalotiopsis psidii (Pat.) Moreases in guava-growing areas and affects (14). Scabby canker can drastically reduce fruit yield during the preharvest stage, and can also lead to fruit losses during postharvest storage (14). In India, $P$. psidii causes postharvest damage of ripe guava fruits (13).

The genus Pestalotiopsis Steyaert is a heterogeneous group of coelomycetous fungi consisting of 205 described species that are differentiated primarily on conidial characteristics such as size, septation, pigmentation, and presence or absence of appendages $(4,19,29)$. Pestalotiopsis is characterized by spores having mostly four-euseptate and pigmented median cells with two to four apical appendages arising as tubular extensions from the apical cell and a centric basal appendage (10). However, Pestalotiopsis is a complex genus and can be difficult to classify to the species level because characters such as growth rate, conidial morphology, and fruiting structure characteristics tend to vary within species (12).

While there are reports of Pestalotiopsis spp. causing symptoms on a variety of hosts $(3,12,24,30,35)$, Pestalotiopsis spp. are primarily thought of as opportunistic pathogens that affect stressed plants (6). However, Pirone (22) reported that 12 different species of Pestalotiopsis caused due, is one of the most common fruit disall developmental stages of guava fruit leaf spots, needle blight, tip blight, and gray blight on a range of hardy ornamentals, including Camellia ( $P$. guepinii (Desm.) Stey.), Gardenia ( $P$. langloisii Guba), Yew (Taxus) (P. funerea (Desm.) Stey.), and Rhododendron (P. macrotricha Kleb.). In a study by Hopkins and McQuilken (9), pathogenicity and host range tests indicated that isolates of $P$. sydowiana (Bres.) Sutton were not host specific and could affect species of hardy ornamentals other than the original host plant. Isolates were also collected from different locations in the UK, confirming the pathogen's widespread distribution in that country (9).

Pestalotiopsis microspora (Speg.) Batista \& Peres appears to be a ubiquitous organism present on tropical and semitropical plants. It has been isolated as a saprophyte on bark and decaying plant material, and as an endophyte from the stems, leaves, flowers, and fruits of hundreds of tropical and subtropical rainforest plants examined by Metz et al. (17). Its relationship to plants seems to be either as a weak pathogen invading aged leaves or as an endophytic symbiont functioning with the higher plant (17). Despite its prevalence, $P$. microspora and its role in plant ecology are poorly understood (17).

Since Pestalotiopsis spp. pose a threat to hardy ornamental production by causing plant loss, reduced plant quality, and disruption of production schedules (9), it is imperative that information be obtained on the identity and biology of the main species that cause plant diseases. Understanding the disease epidemiology and potential for cross-infection are also important so that effective control measures can be developed and implemented (9). Since many hosts are cultivated in close proximity, there is potential for spread of inoculum.

In Hawaii, guava is found throughout the state at various elevations and environmental conditions, and disease symptoms on leaves and fruits are consistently observed. Thus, guava is an excellent model for studying disease to better understand the interaction of susceptible host and pathogen, and the effects of environment on disease development. The objectives of this study were to: (i) identify the causal agent(s) of commonly observed symptoms of scab disease on guava; (ii) 
compare Pestalotiopsis isolates by studying pathogenicity and morphological, cultural, and molecular characteristics; (iii) examine the effect of environmental factors (e.g., temperature) on growth of the pathogen; and (iv) establish pathogenicity and alternative hosts of Pestalotiopsis spp.

\section{MATERIALS AND METHODS}

Field observations and symptoms. Plants were examined in the fields of the Tropical Plant Genetic Resource Management Unit located at the University of Hawaii, Waiakea Agricultural Experiment Station, Hilo, HI, and in surrounding areas. The primary site is $9.7 \mathrm{~km}$ south of Hilo, with an elevation ranging from 175 to 227 $\mathrm{m}$. Maximum and minimum mean temperatures are $28^{\circ} \mathrm{C}$ and $16^{\circ} \mathrm{C}$, respectively. Annual rainfall averages $4,445 \mathrm{~mm}$ and is most abundant during October to February. The soil consists of an extremely stony Papai muck with organic soils formed over mostly fragmental a'a lava. Digital photographs of leaf and fruit symptoms were recorded using a Nikon Coolpix 995 model digital camera.

Collection of isolates. Naturally infected fruit (17 samples) and leaves (6 samples) of more than 40 guava cultivars were collected from fields in Hilo and the surrounding areas. Twenty-three isolates of Pestalotiopsis were obtained from the diseased samples, and an additional nine were collected from other hosts, including wild guava, blueberry (Vaccinium corymbosum), waiawi (Psidium cattleianum), and tea (Camellia sinensis). All fungi were grown on potato dextrose agar (PDA) (Difco Laboratories, Detroit, $\mathrm{MI}$ ) at $24^{\circ} \mathrm{C}$ under continuous illumination, and singlespore cultures were derived from each isolate and stored at room temperature $\left(20^{\circ} \mathrm{C}\right)$ in sterile distilled water (SDW). Cultures were maintained on PDA.

Initial identification and cultural characteristics. The 32 Pestalotiopsis isolates derived from single spores were grown on PDA. Cultures were incubated at $24^{\circ} \mathrm{C}$ in continuous light, and cultural morphology was examined after 7 days. Colony color was defined according to Raynor (23). Spore size was determined by measuring the length and width of 30 to 40 arbitrarily selected conidia from a conidial suspension of each isolate that was prepared in SDW. The isolates were identified initially by comparing morphological and cultural characteristics (i.e., size of conidia, color and length of median cells, thickness and length of apical appendages, and length of basal appendage) to those described in Guba's monograph of Monochaetia and Pestalotia (7).

Temperature effects on mycelial growth. Five replicate, 10-cm-diameter petri dishes containing PDA $(25 \mathrm{ml})$ were inoculated centrally with an agar disk (5 mm diameter) of a representative sample of the isolates of Pestalotiopsis (16 strains) cut from the edge of an actively growing colony on PDA. The isolates were selected based on morphological characters. Representatives exhibiting a broad range of varying morphological characters were included. The effect of temperature on colony diameter was determined after 1,4 , and 7 days at $10,15,22,26,30$, and $35^{\circ} \mathrm{C}$. All temperature experiments were conducted twice.

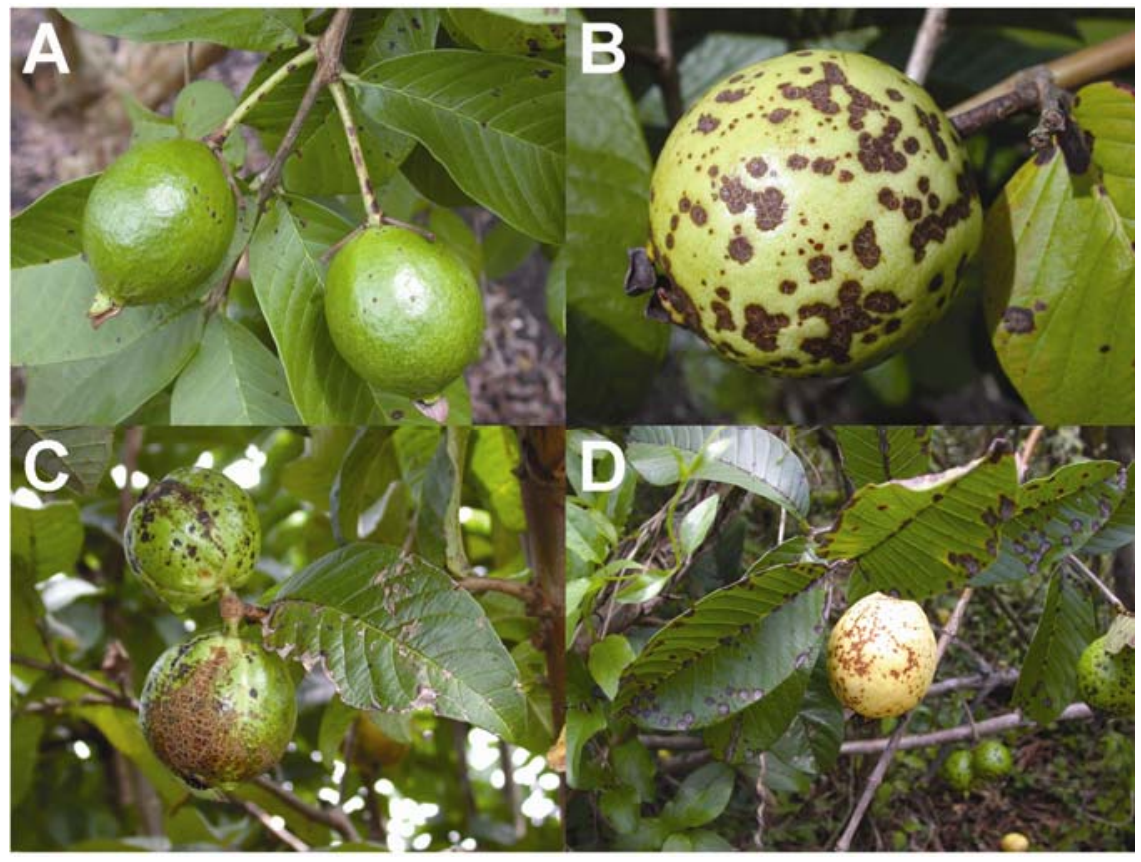

Fig. 1. Most common symptoms of scab disease of guava seen in the field. A, Immature fruit with small, brown, slightly raised lesions. Stem also had reddish-brown lesions. B, Discrete dark brown lesions. C, Coalescing lesions giving rise to scabby appearance. D, Symptoms on mature fruit and leaves.
Pathogenicity tests. Pathogenicity tests consisted of inoculations of guava fruit and leaves removed from the tree. Before inoculation, fruit and leaves were surfacedisinfested by immersion in $10 \%$ bleach solution $(0.5 \%$ sodium hypochlorite) for 2 min, rinsed in SDW, and then air-dried in a laminar flow hood. Fruit and leaves were placed in plastic chambers containing moistened paper towels. Fruit (P. guajava cvs. Lucknow or Lucknow 49) were wounded with a sterile cork borer and inoculated with mycelial disks $(3 \mathrm{~mm}$ diameter) of Pestalotiopsis strains 2B Hong Kong White, Guava 4C, 4-2A Fan Retief, or Guava 1C-1 grown for 5 to 7 days at $28^{\circ} \mathrm{C}$. Healthy leaves of $P$. guajava cvs. Patillo, Kona, or Lucknow 49 were wounded by pressing slightly with a pipette tip, and the disks of mycelium were applied on the wounded and intact leaves.
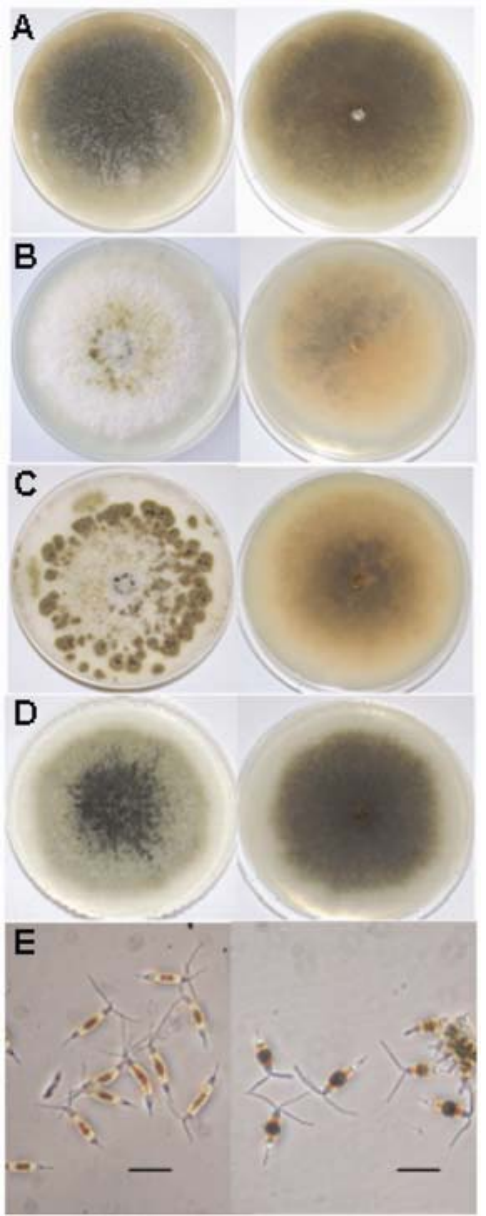

Fig. 2. Colony characteristics on PDA after 7 to 10 days at $26^{\circ} \mathrm{C}$. A, buff (front) (left) and pale luteous (reverse) (right) represented by guava isolate 21. B, pale buff from above and pale buff/pale saffron from below represented by guava isolate 19 . $\mathbf{C}$, pale buff from above and pale buff/pale saffron from below containing areas of greenish glaucous patches scattered on their upper surface represented by guava isolate 3. D, pale olivaceous buff from above and olivaceous buff from below represented by guava isolate 16. E, commonly observed conidia from Pestalotiopsis represented by guava isolate 19 (left) and 8 (right). Bars $=25 \mu \mathrm{m}$. 
Inoculated samples were incubated at $28^{\circ} \mathrm{C}$, and disease incidence and severity were evaluated. Controls were inoculated with PDA disks only. Detached leaves and leaves of 1-year-old, greenhouse-grown guava seedlings (cv. Kona) were also inoculated with a conidial suspension (approximately $10^{7}$ conidia per $\mathrm{ml}$ ). Detached leaves were incubated at $28^{\circ} \mathrm{C}$. Guava seedlings were incubated at $26^{\circ} \mathrm{C}$. Controls were inoculated with SDW. To fulfill Koch's postulates, diseased tissue was placed on water agar and PDA and observed for colonies typical of the pathogen. Experiments were repeated at least twice with similar results.

Cross-inoculation studies. Alternative hosts of Pestalotiopsis strain 2B Hong Kong White were determined using 1-yearold, greenhouse-grown leaves of lychee (Litchi chinensis), rambutan (Nephelium lappaceum), Miltonia orchid, and ginger (Zingiber officinale), with methods described previously.

Molecular characterization. Pestalotiopsis isolates were identified using molecular techniques. Total DNA was extracted from mycelium obtained from cultures of 22 guava isolates and 6 alternative host isolates grown on PDA for 5 to 7 days at $24^{\circ} \mathrm{C}$. A sterile $0.5-\mathrm{cm}^{3}$ cork borer was used to transfer a sample of fungal mycelium into a sterile $1.5-\mathrm{ml}$ microcentrifuge tube. The tube was filled with liquid nitrogen, allowed to evaporate, and then repeated. Five-hundred microliters of lysis buffer $(50 \mathrm{mM}$ Tris-HCl, $50 \mathrm{mM}$ EDTA, $3 \%$ sodium dodecyl sulfate, $1 \% \quad 2-$ mercaptoethanol, and $0.1 \mathrm{mg} / \mathrm{ml}$ Proteinase $\mathrm{K}, \mathrm{pH} 8.0$ ) was added, and the tubes were vortexed and placed in a $65^{\circ} \mathrm{C}$ water bath for $1 \mathrm{~h}$ with vortexing after 30 and $60 \mathrm{~min}$. An equal volume of phenol:chloroform:isoamyl alcohol (25:24:1 $\mathrm{vol} / \mathrm{vol} / \mathrm{vol}$ ) was added. The tubes were mixed and then centrifuged at 14,000 rpm for $15 \mathrm{~min}$. The supernatant was pipetted to a new sterile $1.5-\mathrm{ml}$ tube, and $500 \mu \mathrm{l}$ of ice-cold isopropanol, $65 \mu \mathrm{l}$ of $3 \mathrm{M}$ sodium acetate, and $75 \mu \mathrm{l}$ of $1 \mathrm{M}$ sodium chloride were added. The capped tubes were inverted several times to adequately mix, incubated at $-20^{\circ} \mathrm{C}$ for $30 \mathrm{~min}$, and then centrifuged at 14,000 rpm for $20 \mathrm{~min}$. The supernatant was discarded, and the nucleic acid pellet was washed in $500 \mu \mathrm{l}$ of $70 \%$ ethanol and centrifuged at $14,000 \mathrm{rpm}$ for 5 min. Again, the supernatant was discarded, and the nucleic acid pellet was airdried and resuspended in $20 \mu \mathrm{l}$ of TE with RNase A added. The PCR reaction to amplify the ITS1/5.8 $\mathrm{S}$ rRNA/ITS2 region was based largely on Caetano-Anolles et al. (5) and White et al. (38). The PCR primers had the following base sequences: ITS1: TCCGTAGGTGAACCTGCGG, and ITS4: TCCTCCGCTTATTGATATGC. Primers were synthesized by Integrated DNA Technology (IA). PCR amplification was performed in a 50- $\mu$ l reaction mixture con- taining $4 \mu \mathrm{l}$ template DNA, $3 \mu \mathrm{M}$ of each primer, 1× PCR buffer (supplied with Taq polymerase), $25 \mathrm{mM} \mathrm{MgCl}_{2}, 2 \mathrm{mM}$ dNTPs, and $0.5 \mathrm{U} \mathrm{Taq}$ polymerase. After an initial hot start $\left(95^{\circ} \mathrm{C}\right.$ for $\left.5 \mathrm{~min}\right), 35$ PCR cycles were performed on a MJ Scientific PTC-100 thermocycler using the following conditions: a denaturation step of $95^{\circ} \mathrm{C}$ for $30 \mathrm{~s}$ followed by annealing at $55^{\circ} \mathrm{C}$ for $1 \mathrm{~min}$ and extension at $72^{\circ} \mathrm{C}$ for 1 min, followed by a final extension of $72^{\circ} \mathrm{C}$ for $6 \mathrm{~min}$. Analysis was carried out by adding $3 \mu \mathrm{l}$ of loading buffer to $10 \mu \mathrm{l}$ of PCR products, which were loaded onto a $2 \%$ agarose gel (Invitrogen Co., San Diego, CA) with electrophoresis at $5 \mathrm{Vcm}^{-}$ ${ }^{1}$ and visualized under UV after staining the gel with ethidium bromide. A 1-kb ladder (Invitrogen) was used as a size marker. PCR products were cloned with the TA cloning kit (Invitrogen) according to the manufacturer's recommendations. Plasmid DNA for sequencing was prepared with the Qiagen plasmid miniprep kit according to the recommendations of the manufacturer (Qiagen, Inc., Chatsworth, CA). DNA sequencing was performed at MWG Biotech Inc. (High Point, NC). Sequence data were aligned and similarity searches of the GenBank database were determined using the National Center for Biotechnology Information Blast Network Server (1). A multiple sequence alignment was constructed using CLUSTALX (34) and BOXSHADE 3.21 (8). Phylogenetic analysis was constructed by the Neighbor-Joining method
(25) derived from the ITS $1 / 5.8 \mathrm{~S}$ rDNA/ITS2 sequences.

\section{RESULTS}

Field observations and symptoms. A Pestalotiopsis disease survey on guava was conducted at the Waiakea Agricultural Experiment Station where more than 50 accessions of guava are maintained. Disease symptoms were visible on leaves during nonfruiting seasons and on the exocarp of young fruits (pinhead size) which progressed as fruits got larger. Typical symptoms on fruit began with tiny, watersoaked spots (Fig. 1A). The spots darkened in color and became necrotic as Pestalotiopsis sp. infected the damaged tissue. Over time, the tiny spots expanded to discrete, circular, dark brown to black spots (Fig. 1B). Also commonly observed were multiple lesions that coalesced to form an overall scabbed appearance. As the fruit developed, the small, corky lesions often tore open, giving rise to raised, corky scabs (Fig. 1C). Symptoms on leaves began as small dark brown spots that expanded to become gray/light brown circles surrounded by a dark brown border (Fig. 1D). In severe cases, lesions developed on large portions of a single leaf. Lesions were also observed on stems of fruit (Fig. 1A).

Isolation and identification. Twentythree isolates of Pestalotiopsis were collected from a range of known guava accessions from the Hilo field and surrounding areas (Table 1). Isolates were obtained from immature and mature fruit, and foli-

Table 1. Isolates of Pestalotiopsis used in this study, their hosts, and sample origin

\begin{tabular}{|c|c|c|c|}
\hline Isolate & Name & Host & Plant part \\
\hline 1 & 2B Hong Kong White & Psidium guajava & Immature guava fruit \\
\hline 2 & Blueberry 1-1A & Vaccinium corymbosum & Leaf lesion \\
\hline 3 & Guava 1C-2 & Psidium guajava & Leaf lesion \\
\hline 4 & 6B-1B 7198 & Psidium guajava & Mature guava fruit \\
\hline 5 & 4-3B Fan Retief & Psidium guajava & Mature guava fruit \\
\hline 6 & Emerald blueberry leaf $\mathrm{H} 20$ & Vaccinium corymbosum & Leaf lesion \\
\hline 7 & 1A Pearl Guava & Psidium guajava & Mature guava fruit \\
\hline 8 & 1A-1 Guava & Psidium guajava & Mature guava fruit \\
\hline 9 & 7B Lucknow & Psidium guajava & Immature guava fruit \\
\hline 10 & Tea\#1 & Camellia sinensis & Leaf lesion \\
\hline 11 & Wild Guava\#1 & Psidium guajava & Leaf lesion \\
\hline 12 & 4-4 Fan Retief & Psidium guajava & Mature guava fruit \\
\hline 13 & Guava 4C & Psidium guajava & Mature guava fruit \\
\hline 14 & \#5 Indonesia seedless & Psidium guajava & Leaf lesion \\
\hline 15 & Waiawi\#2-1 & Psidium cattleianum & Leaf lesion \\
\hline 16 & 4-2A Fan Retief & Psidium guajava & Mature guava fruit \\
\hline 17 & Guava 1C-1 & Psidium guajava & Leaf lesion \\
\hline 18 & HPSI 51-1 Guava leaf & Psidium guajava & Leaf lesion \\
\hline 19 & 4-2 N97-55 OGN & Psidium guajava & Mature guava fruit \\
\hline 20 & 4-1A Fan Retief & Psidium guajava & Mature guava fruit \\
\hline 21 & Guava 1B & Psidium guajava & Mature guava fruit \\
\hline 22 & 1C Pearl Guava & Psidium guajava & Mature guava fruit \\
\hline 23 & 4-3 Fan Retief & Psidium guajava & Mature guava fruit \\
\hline 24 & Guava 6B & Psidium guajava & Mature guava fruit \\
\hline 25 & 5A 7197 & Psidium guajava & Leaf lesion \\
\hline 26 & Guava 2B & Psidium guajava & Mature guava fruit \\
\hline 27 & 1A-1 Indonesian SDLS & Psidium guajava & Leaf lesion \\
\hline 28 & Guava 2 & Psidium guajava & Immature guava fruit \\
\hline 29 & Waiawi leaf\#1-1 & Psidium cattleianum & Leaf lesion \\
\hline 30 & Waiawi fruit\#1 & Psidium cattleianum & Immature waiawi fruit \\
\hline 31 & Emerald blueberry apex H20 & Vaccinium corymbosum & Leaf lesion \\
\hline 32 & Emerald blueberry leaf & Vaccinium corymbosum & Leaf lesion \\
\hline
\end{tabular}


age with disease symptoms. An additional nine isolates were collected from wild guava, blueberry, waiawi, and tea (Table $1)$. The isolates were named and given a corresponding number. The fungi were maintained on PDA and stored in SDW for additional studies. All isolates were identified as Pestalotiopsis sp. on the basis of conidial morphology (Fig. 2E). All had five-celled conidia, of which apical and basal cells were hyaline, and the three median cells ranged from light brown and dark brown to varying shades of olive green. Measurements of conidia revealed few differences in size among isolates. Eleven Pestalotiopsis strains were compared (Table 2). Conidia varied from $21.7 \pm 0.5$ (standard error) to $27.7 \pm$ $0.4 \mu \mathrm{m}$ mean length and $5.5 \pm 0.1$ to $7.5 \pm$ $0.2 \mu \mathrm{m}$ mean width. Basal appendages were hyaline, straight or slightly curved, and varied from $2.8 \pm 0.1$ to $5.3 \pm 0.3 \mu \mathrm{m}$ mean length. Numbers of apical appendages ranged from two to four, with three being the most common. The appendages showed the most size variation, with mean lengths that ranged from $11.8 \pm 0.6$ to $26.5 \pm 1.1 \mu \mathrm{m}$. The isolated fungi were identified tentatively as $P$. microspora, $P$. clavispora (Atk.) Stey., and P. psidii based on morphological and cultural characteristics using Guba's monograph (7) and other descriptions previously reported (14).

Table 2. Characteristics of conidia of Pestalotiopsis isolates

\begin{tabular}{lccccc}
\hline Isolate & $\begin{array}{c}\text { Conidia } \\
\text { length }(\boldsymbol{\mu m})\end{array}$ & $\begin{array}{c}\text { Conidia } \\
\text { width }(\boldsymbol{\mu m})\end{array}$ & $\begin{array}{c}\text { Apical } \\
\text { appendage } \\
\text { length }(\boldsymbol{\mu m})\end{array}$ & $\begin{array}{c}\text { Basal appendage } \\
\text { length }(\boldsymbol{\mu m})\end{array}$ & $\begin{array}{c}\text { No. of apical } \\
\text { appendages } \\
\text { (range) }\end{array}$ \\
\hline 8 & $24.8 \pm 0.4^{\mathrm{a}}$ & $7.3 \pm 0.1$ & $19.0 \pm 0.7$ & $4.3 \pm 0.3$ & $2-4$ \\
13 & $21.8 \pm 0.3$ & $6.3 \pm 0.2$ & $17.8 \pm 0.7$ & $2.9 \pm 0.2$ & $2-4$ \\
14 & $22.8 \pm 0.4$ & $7.5 \pm 0.1$ & $18.3 \pm 0.7$ & $4.0 \pm 0.3$ & $2-4$ \\
16 & $21.7 \pm 0.5$ & $5.6 \pm 0.2$ & $14.1 \pm 0.5$ & $2.8 \pm 0.1$ & $2-3$ \\
17 & $24.3 \pm 0.5$ & $5.3 \pm 0.1$ & $11.8 \pm 0.6$ & $4.3 \pm 0.4$ & $2-3$ \\
19 & $24.5 \pm 0.5$ & $5.5 \pm 0.2$ & $15.8 \pm 0.5$ & $5.3 \pm 0.3$ & $2-3$ \\
20 & $24.1 \pm 0.4$ & $6.1 \pm 0.2$ & $19.1 \pm 0.6$ & $2.9 \pm 0.2$ & $2-3$ \\
21 & $24.8 \pm 0.3$ & $6.8 \pm 0.2$ & $21.3 \pm 0.6$ & $4.8 \pm 0.3$ & $2-3$ \\
24 & $27.3 \pm 0.5$ & $7.0 \pm 0.2$ & $22.5 \pm 1.0$ & $5.0 \pm 0.3$ & $2-4$ \\
27 & $24.5 \pm 0.5$ & $7.5 \pm 0.2$ & $26.5 \pm 1.1$ & $4.0 \pm 0.3$ & $2-3$ \\
32 & $27.7 \pm 0.4$ & $5.2 \pm 0.1$ & $13.3 \pm 0.4$ & $4.5 \pm 0.2$ & $2-3$ \\
\hline
\end{tabular}

${ }^{\text {a }}$ Each value is the mean \pm SE from measurements of 30 to 40 conidia.

Cultural characteristics. Typical cultural and morphological characteristics are shown in Figure 2. On PDA plates, most of the isolates first developed grayish to white zonate colonies that later developed color and small, acervular conidiomata. The colors became darker as fungal age increased. A representative subsample of the isolates of Pestalotiopsis (26 strains) could be separated into three main groups based on their color on PDA (Fig. 2A, B, and D). However, color groups did not separate into species. The first group, buff (front) and pale luteous (reverse), contained guava isolates $1,5,7,8,9,13,21,22,24,26$, and 27, and Pestalotiopsis isolates 6, 11, and 30 , which were collected from alternative hosts (Fig. 2A). The second group, pale buff (front) and pale buff/pale saffron (reverse), contained guava isolates $4,14,19$, 20 , and 25, and blueberry isolate 31 (Fig. 2B). While isolates 3, 17, 28, and 32 also fell into this category, these fungal isolates contained greenish, glaucous patches scattered on their surface (Fig. 2C). The third group contained isolates 12 and 16, which were pale olivaceous buff (front) and olivaceous buff (reverse) (Fig. 2D). Acervuli were black for all isolates examined (Table 3). However, production varied from abundant (throughout the entire PDA plate) (isolates 1, 4, 8, 19, 20, 21, and 27) to moderate (concentrated in the center of the PDA plate) (isolates 12, 14, 16, 25, and 31) to sparse (very few on PDA plate)

Table 3. Colony morphology in culture ${ }^{\mathrm{a}}$ of isolates of Pestalotiopsis and BLASTN results of the ITS and rDNA sequences

\begin{tabular}{|c|c|c|c|c|c|}
\hline Isolate & Name & Front view & Reverse view & Acervuli & BLAST search ID \\
\hline 1 & 2B Hong Kong White & Buff & Pale luteous & Black; abundant & Pestalotiopsis sp. GJ-1 \\
\hline 2 & Blueberry 1-1A & $\mathrm{nd}^{\mathrm{b}}$ & nd & nd & nd \\
\hline 3 & Guava 1C-2 & Pale buff w/greenish glaucous & Pale buff/pale saffron & Black; sparse & nd \\
\hline 4 & 6B-1B 7198 & Pale buff & Pale buff/pale saffron & Black; sparse & nd \\
\hline 5 & 4-3B Fan Retief & Buff & Pale luteous & Black; abundant & nd \\
\hline 6 & Emerald blueberry leaf H20 & Buff & Pale luteous & None & Pestalotiopsis microspora \\
\hline 7 & 1A Pearl Guava & Buff & Pale luteous & Black; sparse & Pestalotiopsis sp. GJ-1 \\
\hline 8 & 1A-1 Guava & Buff & Pale luteous & Black; abundant & Pestalotiopsis sp. GJ-1 \\
\hline 9 & 7B Lucknow & Buff & Pale luteous & None & Pestalotiopsis microspora \\
\hline 10 & Tea\#1 & nd & nd & nd & Pestalotiopsis sp. GJ-1 \\
\hline 11 & Wild Guava\#1 & Buff & Pale luteous & Black; sparse & Pestalotiopsis microspora \\
\hline 12 & 4-4 Fan Retief & Pale olivaceous buff & Olivaceous buff & Black; moderate & Pestalotiopsis sp. GJ-1 \\
\hline 13 & Guava 4C & Buff & Pale luteous & Black; sparse & Pestalotiopsis clavispora \\
\hline 14 & \#5 Indonesia seedless & Pale buff & Pale buff/pale saffron & Black; moderate & Pestalotiopsis sp. GJ-1 \\
\hline 15 & Waiawi\#2-1 & nd & nd & nd & Pestalotiopsis neglecta \\
\hline 16 & 4-2A Fan Retief & Pale olivaceous buff & Olivaceous buff & Black; moderate & Pestalotiopsis disseminata \\
\hline 17 & Guava $1 \mathrm{C}-1$ & Pale buff w/greenish glaucous & Pale buff/pale saffron & Black; sparse & Pestalotiopsis microspora \\
\hline 18 & HPSI 51-1 Guava leaf & nd & nd & nd & Pestalotiopsis sp. GJ-1 \\
\hline 19 & 4-2 N97-55 OGN & Pale buff & Pale buff/pale saffron & Black; abundant & Pestalotiopsis microspora \\
\hline 20 & 4-1A Fan Retief & Pale buff & Pale buff/pale saffron & Black; abundant & Pestalotiopsis sp. GJ-1 \\
\hline 21 & Guava 1B & Buff & Pale luteous & Black; abundant & Pestalotiopsis sp. GJ-1 \\
\hline 22 & 1C Pearl Guava & Buff & Pale luteous & None & Pestalotiopsis sp. GJ-1 \\
\hline 23 & 4-3 Fan Retief & nd & nd & nd & Pestalotiopsis sp. GJ-1 \\
\hline 24 & Guava 6B & Buff & Pale luteous & Black; sparse & Pestalotiopsis sp. GJ-1 \\
\hline 25 & 5A 7197 & Pale buff & Pale buff/pale saffron & Black; moderate & Pestalotiopsis sp. GJ-1 \\
\hline 26 & Guava 2B & Buff & Pale luteous & None & Pestalotiopsis microspora \\
\hline 27 & 1A-1 Indonesian SDLS & Buff & Pale luteous & Black; abundant & Pestalotiopsis microspora \\
\hline 28 & Guava 2 & Pale buff w/greenish glaucous & Pale buff/pale saffron & None & Pestalotiopsis microspora \\
\hline 29 & Waiawi leaf\#1-1 & nd & nd & nd & Pestalotiopsis neglecta \\
\hline 30 & Waiawi fruit\#1 & Buff & Pale luteous & None & Pestalotiopsis sp. GJ-1 \\
\hline 31 & Emerald blueberry apex $\mathrm{H} 20$ & Pale buff & Pale buff/pale saffron & Black; moderate & Pestalotiopsis microspora \\
\hline 32 & Emerald blueberry leaf & Pale buff w/greenish glaucous & Pale buff/pale saffron & Black; sparse & Pestalotiopsis microspora \\
\hline
\end{tabular}

${ }^{a}$ Fungi were grown on potato dextrose agar with continuous light for 7 days.

${ }^{\mathrm{b}}$ nd $=$ not determined. 
(isolates 3, 4, 7, 11, 13, 17, 24, and 32) (Table 3). Isolates 6, 9, 22, 26, 28, and 30 did not produce visible acervuli within 12 days of growth on PDA (Table 3). an effect on the colony diameter of the 16 isolates of Pestalotiopsis examined (Fig. 3). When grown on PDA in the dark, all isolates grew at a temperature range of 10 to $35^{\circ} \mathrm{C}$, with optimum growth between $22^{\circ} \mathrm{C}$ and $28^{\circ} \mathrm{C}$ (Fig. 3). Within 7 days, the diameter of the majority of the isolates measured approximately $80 \mathrm{~mm}$, the diameter of the PDA plate. However, certain isolates exhibited a slower growth rate within the optimum temperature range of $22^{\circ} \mathrm{C}$ to $28^{\circ} \mathrm{C}$ compared with the majority of the isolates. Isolates 1,20 , and 28 grew more slowly at $26^{\circ} \mathrm{C}$ and $30^{\circ} \mathrm{C}$ and reached only $58 \pm 4.4$ to $69 \pm 4.4 \mathrm{~mm}$ (mean diameter \pm SE) after 7 days. Isolate 23 exhibited a slower growth rate, only reaching a maximum diameter of growth of $67 \pm 3.9$ $\mathrm{mm}$ at $30^{\circ} \mathrm{C}$ and $56 \pm 4.6 \mathrm{~mm}$ at $26^{\circ} \mathrm{C}$. In contrast, isolate 14 exhibited a wider range of growth, reaching $62 \pm 2.5 \mathrm{~mm}$ at $15^{\circ} \mathrm{C}$. When temperature experiments were repeated, colony diameters were virtually identical for all Pestalotiopsis strains tested.

Pathogenicity tests. To confirm pathogenicity and to determine if wounding was
Temperature effects. Temperature had

necessary for infection, mycelial plugs containing conidia were used as inoculum. Pale green to yellow guava fruit (cvs. Lucknow or Lucknow 49) were inoculated in the laboratory with four Pestalotiopsis isolates (2B Hong Kong White, Guava 4C, 4-2A Fan Retief, or Guava 1C-1) and maintained in a moist chamber for 7 to 10 days. Brown, corky lesions resembling symptoms that occurred in the field were observed surrounding the inoculation sites beginning around day 5 (Fig. 4A). Symptoms were not observed on control fruit inoculated with agar media (data not shown). Young, fully developed leaves from $P$. guajava cvs. Patillo, Kona, or Lucknow 49 were also inoculated in the laboratory with the Pestalotiopsis strains and maintained in a moist chamber for up to 20 days. Light brown lesions surrounded by a dark brown border, which resembled symptoms that occurred in the field, were observed on leaves after 4 to 7 days, with symptoms continuing to develop (Fig. 4B). Symptoms were not usually observed on nonwounded leaves (Fig. 4B, arrow). Symptoms were not observed on control leaves inoculated with agar media (data not shown). Wounding was still necessary for symptom development when a conidial suspension was inoculated onto detached leaves or guava seedlings.

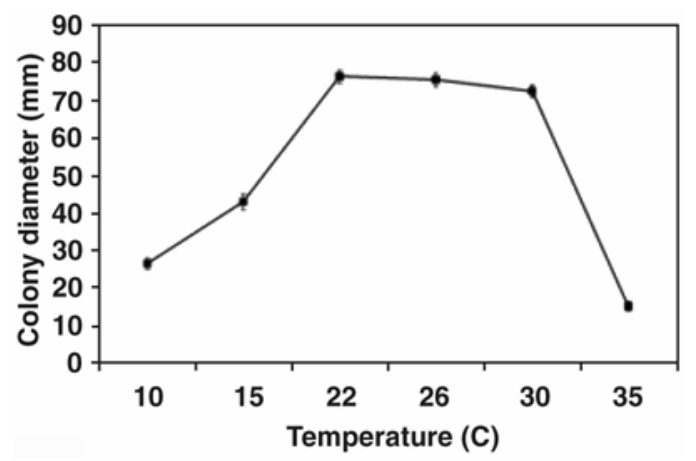

Fig. 3. Influence of temperature on mycelial growth of Pestalotiopsis isolated from diseased Hawaiian guava fruit and leaves. Growth after 7 days on potato dextrose agar (PDA). Each bar represents mean \pm $\operatorname{SEM}(n=16)$.

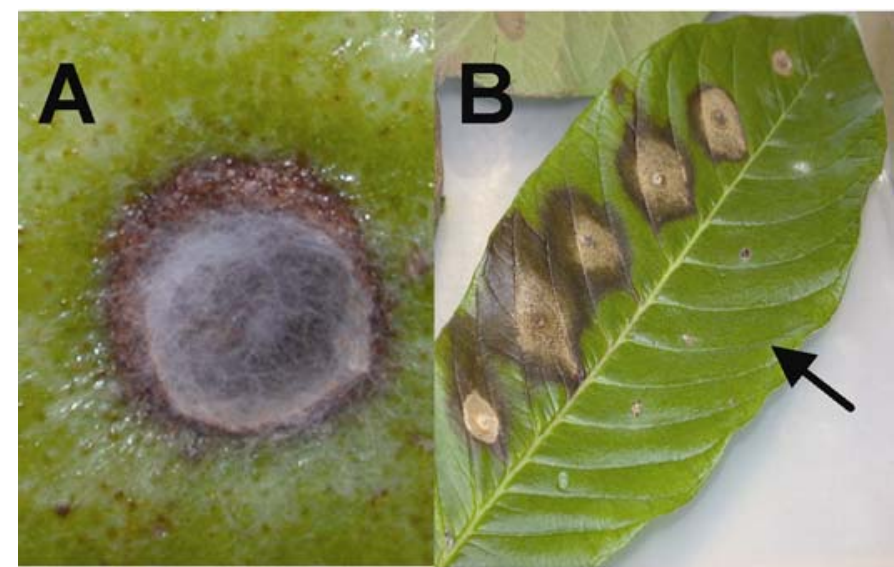

Fig. 4. Symptoms of scab disease on guava. A, fruit cv. Lucknow, 6 days postinfection. B, leaf cv. Patillo, 19 days postinfection with wounding versus nonwounding (arrow).
Symptoms were delayed (lesions visible after 10 days) and lesion sizes were reduced. The fungi were reisolated from the lesions of the diseased fruit and leaves and were identical to the original isolates. Although lesions were produced by the four Pestalotiopsis strains on all guava cultivars tested, varying levels of host susceptibility were observed.

Cross-inoculation studies. The development of a necrotic zone or lesion of at least $2.0 \mathrm{~mm}$ beyond the inoculation site was considered positive for the ginger, rambutan, lychee, and Miltonia orchid leaves. Pestalotiopsis 2B Hong Kong White produced lesions on all alternative hosts tested, and in some cases, wounding was not necessary for symptom development; however, symptoms on ginger and lychee were enhanced by wounding (data not shown). Symptoms were not observed on control leaves inoculated with agar media. Experiments were repeated twice with similar results.

Molecular characterization. DNA from 22 isolates from guava and 6 isolates from alternative hosts was amplified when the PCR reaction was performed using primers ITS1 and ITS4. The corresponding PCR region amplified was the ITS rDNA sequence of region 1 and 2, which also included the 5.8S rDNA gene. The PCR product was approximately 550 to $615 \mathrm{bp}$ for all isolates (Fig. 5). High-quality sequences of approximately 550 nucleotides of each isolate were used for analysis. The sequences were aligned and the 28 strains could be separated into two main groups. Differences in nucleotides were observed among the isolates which were concentrated in the ITS regions. The 5.8S rDNA was more highly conserved among Pestalotiopsis spp. Each PCR product sequence was compared by BLAST search (1), and the isolates were confirmed to the species level (Table 3). Both DNA strands were sequenced for verification. Sequences of the ITS1/5.8S rDNA/ITS2 region from 28 isolates of Pestalotiopsis were deposited into the GenBank database with accession numbers DQ000991 through DQ001018. A phylogenetic tree was produced from the analysis of the aligned sequences of the ITS1/5.8S rDNA/ITS2 generated in this study (Fig. 6). The tree separates the Pestalotiopsis isolates into two distinct clusters, with one clade (isolates 6, 9, 15, 16, 17, $19,26,28,29,31$, and 32) containing a level of divergence from the other strains mainly in the ITS regions.

\section{DISCUSSION}

Currently, there is very little information known about the presence, prevalence, and etiology of scabby canker of guava in Hawaii. Our disease survey revealed similar symptoms on the leaves and fruit of more than 50 guava accessions, regardless of cultivar or location. Pestalotiopsis spp. were consistently isolated and identified 
from diseased samples. According to studies by Patel et al. (21), Pestalotiopsis caused symptoms on green fruit, but seldom on leaves. This was not the case in our study; Pestalotiopsis spp. were isolated from lesions on fruit at all levels of maturity and were also the causal agents of abundant lesions on leaves. Pestalotiopsis spp. were also commonly isolated from wild guava, waiawi, and tea that were in close proximity to guava fields and, thus, could serve as sources of inoculum. In a study by Pandey (20), P. psidii was found to be present on a high proportion of flowers even though no disease symptoms were found on any of the floral parts, suggesting flowers may be a source of inoculum for the fruit (20). Inoculum sources of $P$. $s y$ dowiana for container-grown ericaceous crops included diseased stock plants, crop debris, nursery soils, used growing media, pots and floor covering, and dust collected from greenhouse walkways (17).

The ability of these fungi to affect other hosts warrants attention. In studies by McQuilken and Hopkins (16), isolates were not host-specific and affected other species of ericaceous plants, with typical symptoms including browning of foliage, stems, and roots, and the presence of black or greenish black acervuli on diseased tissue. In another study (39), a leaf spot disease which had not been seen in Tottori Prefecture was considered a serious problem for Japanese persimmon fruits (Diospyros kaki). In a study by Yasuda et al. (40), P. longiseta (Speg.) Dai \& Kobayashi was the predominant species on persimmon, but $P$. acaciae (Thum.) Yokoyama \& Kaneko, $P$. crassiuscula Stey., and $P$. glandicola (Cast.) Stey. were also isolated. All of these species have also been reported to be pathogens of broad-leaved trees or conifers $(27,28)$ and are regarded as omnivorous fungi. It is thought that vegetation around the persimmon orchard may have contributed to the prevalence of Pestalotiopsis spp. occurring on persimmon trees (39). Taguchi et al. (31) provided evidence through inoculation experiments and host range studies that isolates of Pestalotiopsis spp. are generally not host-specific.

While the majority of the Pestalotiopsis isolates from guava and the alternative hosts in our study looked similar, morphological and cultural differences did exist, and species could not be grouped based solely on colony or conidia morphology. On PDA, cultures were typically various shades of luteous and buff with pink or peach hues, which became darker as the age of the fungal culture increased. The majority of the Pestalotiopsis isolates produced acervuli in culture, but the amounts tended to vary (Table 3). However, acervuli formed under all temperature conditions tested. Conidia were five-celled with the apical and basal cells hyaline for all isolates. The three median cells were typi-

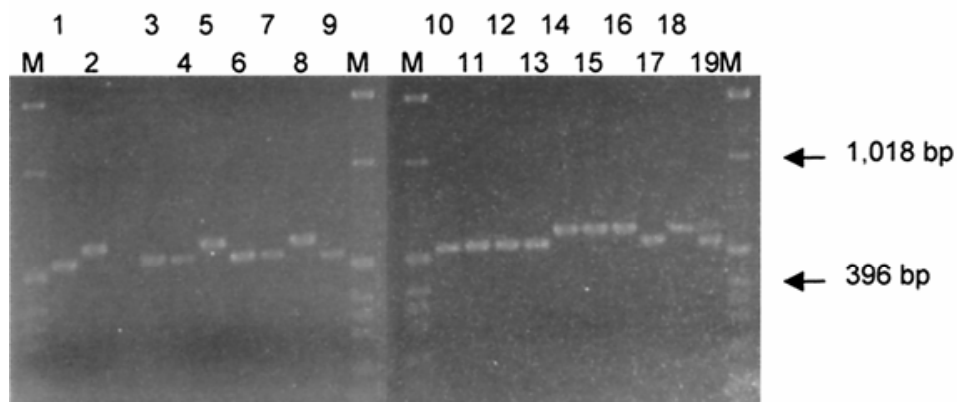

Fig. 5. Amplification products and markers in agarose gels stained with ethidium bromide for ITS ribosomal DNA primers ITS1 and ITS4 and photographed using transmitted UV light. Isolates of Pestalotiopsis spp. are indicated across the top. Marker used was 1-kb ladder, and molecular weights are shown on the right of the gel. M, 1-kb ladder; lane 1, 2B Hong Kong White; lane 2, Blueberry 1-1A; lane 3, 6B1B 7198; lane 4, 4-3B Fan Retief; lane 5, Emerald blueberry leaf H20; lane 6, 1A Pearl Guava; lane 7, 1A-1 Guava; lane 8, 7B Lucknow; lane 9, Tea\#1; lane 10, Wild Guava\#1; lane 11, 4-4 Fan Retief; lane 12, Guava 4C; lane 13, \#5 Indonesia seedless; lane 14, Waiawi\#2-1; lane 15, 4-2A Fan Retief; lane 16, Guava 1C-1; lane 17, HPSI 51-1 Guava leaf; lane 18, 4-2 N97-55 OGN; lane 19, 4-1A Fan Retief.

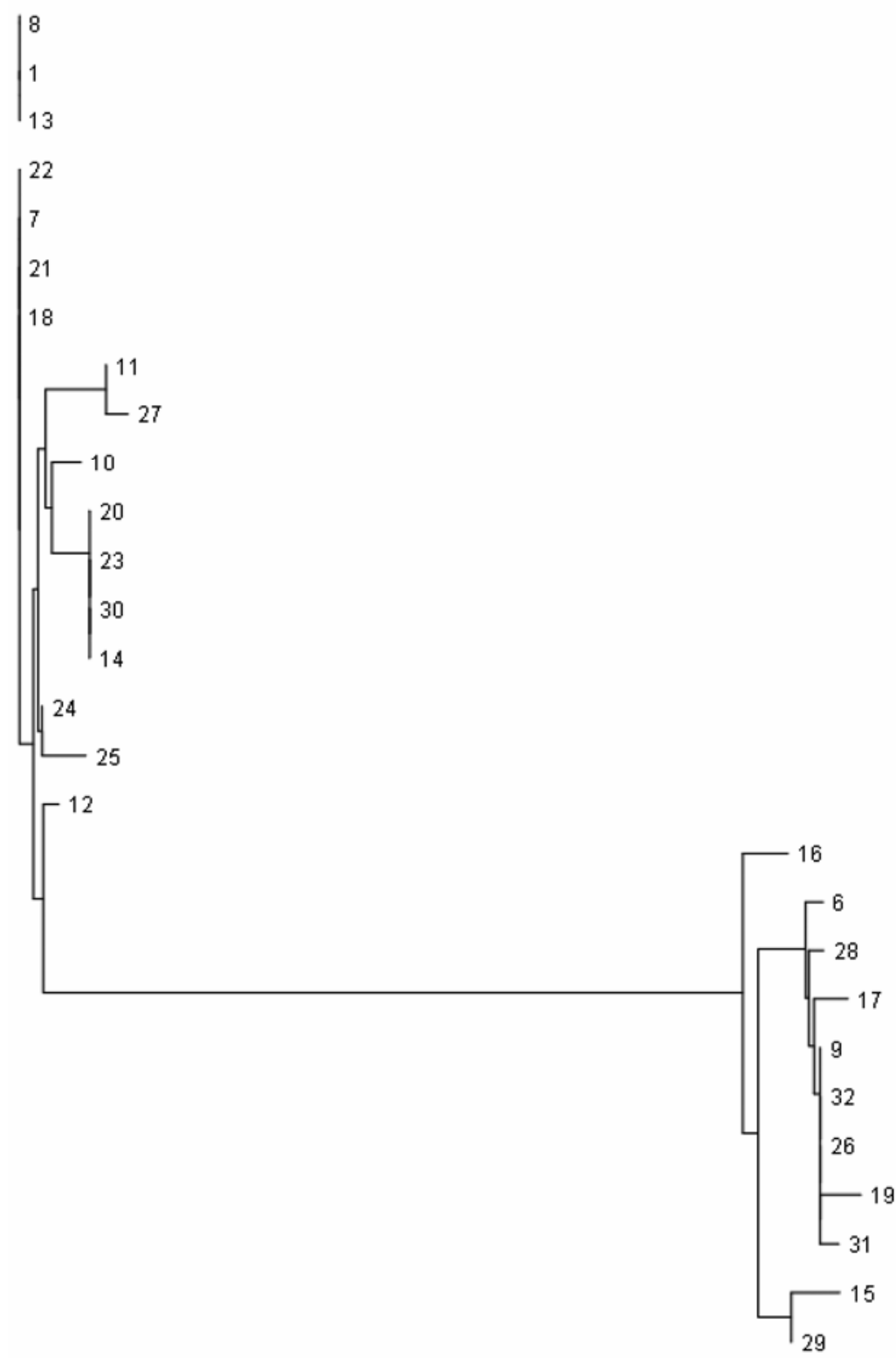

0.01

Fig. 6. Phylogenetic tree of Pestalotiopsis isolates based on the ITS and 5.8S rDNA gene. The tree was produced using the Neighbor-Joining algorithm. A bootstrap analysis was performed with 100 repetitions. Scale bar indicates estimated $1 \%$ sequence divergence. 
cally olivaceous to dark brown or light brown. Temperature affected mycelial growth, with optimum growth occurring around $26^{\circ} \mathrm{C}$ (Fig. 3). In a study by Patel et al. (21), $P$. psidii grew well at $26^{\circ} \mathrm{C}$, but failed to grow at temperatures above $32^{\circ} \mathrm{C}$ or below $5^{\circ} \mathrm{C}$. While the lower limits are similar to our findings, the Pestalotiopsis guava strains we isolated were able to grow at $35^{\circ} \mathrm{C}$, albeit at greatly reduced rates. Although the in vitro studies may not directly simulate the conditions of the natural environment, the results provide an insight to the likely behavior and growth of the pathogen in nature. The presence of multiple species of Pestalotiopsis that can thrive over a wide range of temperatures indicates that inoculum capable of causing scab disease on guava will remain viable through a variety of environmental conditions.

Koch's postulates were confirmed, and the cross-infection potential of the Pestalotiopsis isolates was investigated. Wounding prior to inoculation was either necessary for disease development, as was the case for guava, rambutan, tea, and Miltonia orchids, or enhanced symptom development, as was seen for ginger and lychee. Hopkins and McQuilken (9) showed that with $P$. sydowiana, damage to the foliage of unrooted cuttings was necessary prior to inoculation with a spore suspension of the pathogen to produce symptoms. Studies with other species of Pestalotiopsis have also found that nonwounded samples remained symptomless (24). After 6 days, only leaf-wounded Silky Hakea (Hakea sericea) shrubs infected by $P$. funerea exhibited lesions identical to those observed in field plants (26). White (37) showed that infection by $P$. macrotricha occurred only when Rhododendron leaves were subjected to abrasions, scalding, or pinpricks. Camellia, Rhododendron, and a conifer (Thuja spp.) showed symptoms of infection by different species of Pestalotiopsis after the foliage was injured by either pesticide damage or sun scald (9). Consequently, growers may be able to minimize infection by avoiding physical plant damage and by growing plants to avoid stress (9). High temperatures and relative humidity also favored symptom development. Kaushik et al. (13) found that canker of ripe guava fruits required a humid atmosphere of high temperatures ( 25 to $35^{\circ} \mathrm{C}$ ) and relative humidity ( 80 to $100 \%$ ) for maximum disease development. In a study by Tuset et al. (36), unusual climatic conditions including heavy rainfall were favorable for disease development. According to Tuset et al. (36), the hot and dry conditions that usually occur during flowering, growing, and maturation of persimmon fruits normally prevent dissemination of inoculum and infection of leaves.

Cultural and molecular characterization techniques were used to compare the genetic relationship of our Pestalotiopsis isolates. While the isolates could be placed into groups according to color, conidial morphology, or molecular analysis of the ITS regions, it was difficult to maintain the groups when similarities were based on all of these characters simultaneously. In other words, traditional morphology-based classification schemes did not always agree with phylogenetic analysis. Even though three color combinations on PDA were identified (Fig. 2), intensities of the colors varied, which is why it is difficult to use them as a reliable character for taxonomic classification at the species level. However, pigmented median cells of conidia seemed to form a close relationship (Fig. 2) and appear useful for taxonomic purposes. Results of studies by Jeewon et al. (11) indicated that pigmentation of median cells of conidia was a sound diagnostic character for species differentiation. A close relationship among pigmented median cells has been suggested by numerous taxonomists $(7,29)$. Pigmentation in Pestalotiopsis is the result of deposition of melanin granules within the cell matrix. The mean lengths of apical and basal appendages have also been used as important taxonomic characters to delineate species; from the phylogenies generated in studies by Jeewon et al. (11), it can be seen that species sharing similar apical appendage length are closely related to each other. Conidial length of our Pestalotiopsis isolates showed some variation, but conidial width seemed to agree with the molecular data (Table 2 and Fig. 6). According to Jeewon et al. (11), molecular data do not tend always to reveal a close relationship among species with similar conidial forms. Our results tended to support the findings of Jeewon et al. (11) when overall conidial form was analyzed. Isolates from both phylogenetic groups were pathogenic on guava fruit and leaves. This information supports the complex nature of the genus and the difficulty in classifying it at the species level.

In certain parts of the world, changes in production methods for hardy ornamentals have resulted in increasing problems with disease (9). After known major pathogens were brought under control by improved management techniques and the use of effective but highly specific fungicides, plants became more vulnerable to attack by less competitive pathogens which had previously been considered weak or secondary (9). Pestalotiopsis spp. were formerly regarded as weak, opportunistic pathogens that caused little damage to hardy ornamentals $(6,22)$; however, in the past 10 years reports of these pathogens causing widespread damage to a number of container-grown plant species (9) are increasing. During recent seasons, increasing numbers of damaging infections of heather (Calluna vulgaris and Erica spp.), Rhododendron, and conifers by Pestalotiopsis spp. were found on plant samples submitted by growers to the SAC Crop Health Centre (9). This phenomenon has the po- tential to occur in many economically important crops because of the widespread nature of Pestalotiopsis.

This study helped to identify the main species and widespread nature of Pestalotiopsis affecting guava in Hawaii (P. microspora, $P$. clavispora, $P$. sp. GJ-1, and $P$. disseminata (Thum.) Stey.), as well as some of the morphological and environmental characteristics of selected isolates. Difficulties did arise when comparisons were made using both physiological and molecular data for some of the Pestalotiopsis isolates. Isolates 11 and 27 were in one clade of the dendrogram, whereas all the other P. microspora isolates fell in the other clade. Using molecular data and sequence analysis for naming purposes, isolates 11 and 27 matched most closely to $P$. microspora. However, depending on the length of nucleotides used, it is possible to classify the isolates as strain GJ-1 or $P$. clavispora, which seemed more reasonable considering their location on the dendrogram. Using conidial morphology, the isolates can be classified as $P$. clavispora, particularly due to the length of the appendages. PCR analysis and the size of the ITSrDNA fragment amplified indicated that the isolates were placed in the proper clade. These results lend to further support of the difficulties in classification of Pestalotiopsis species. It appears obvious from our phylogenetic study that host specificity is not the best way to examine genetic relatedness.

To our knowledge, this is the first study to provide evidence that numerous species of Pestalotiopsis are capable of causing scabby fruit canker on guava in Hawaii. This is also the first time molecular methods were used to identify Pestalotiopsis spp. on guava in Hawaii. Results showed that pathogen host range and host plant resistance are particularly important issues. For example, tea gray blight caused by $P$. longiseta is a serious disease in the main tea-growing districts of Japan; however, there are considerable differences in the susceptibility to $P$. longiseta among the tea cultivars $(32,33)$. Further studies are currently underway to determine if variation in resistance exists in available guava germplasm in Hawaii. In addition, screening for host resistance in a variety of tropical fruit crops grown in Hawaii is currently underway. With the knowledge gained from these and additional studies, effective and reliable control strategies can be developed. Due to its prevalence throughout the world and its broad host range, Pestalotiopsis is a potent plant pathogen that has gone largely unrecognized. Its potential to cause yield losses in economically important crops warrants further study of Pestalotiopsis spp.

\section{ACKNOWLEDGMENTS}

We thank K. Nishijima and P. Follett for presubmission reviews. We also thank R. Keith and J. Enoka for their technical assistance. 


\section{LITERATURE CITED}

1. Altschul, S. F., Gish, W., Miller, W., Myers, E. W., and Lipman, D. J. 1990. Basic local alignment search tool. J. Mol. Biol. 215(3):403-410.

2. Anonymous. 2004. Statistics of Hawaiian Agriculture, 2003. Hawaii Agricultural Statistics Service, Honolulu.

3. Bera, S., and Purkayastha, R. P. 1992. Physiological studies on strains of Pestalotiopsis versicolor isolated from a mangrove plant. J. Mycopathol. Res. 30:157-165.

4. CABI Bioscience database, 2001. Published online.

5. Caetano-Anolles, G., Trigiano, R. N., and Windham, M. T. 2001. Patterns of evolution in Discula fungi and the origin of dogwood anthracnose in North America, studied using arbitrarily amplified and ribosomal DNA. Curr. Genet. 39:346-354.

6. Coyier, D. L., and Roane, M. K. 1987. Compendium of Rhododendron and Azalea Diseases. American Phytopathological Society, St. Paul, MN.

7. Guba, E. F. 1961. Monograph of Pestalotia and Monochaetia. Harvard University Press, Cambridge, MA.

8. Hoffman, K., and Baron, M. D. 1998. Boxshade Multiple Sequence Alignment display program. Freely available from michael. baron@bbsrc.ac.uk.

9. Hopkins, K. E., and McQuilken, M. P. 2000. Characteristics of Pestalotiopsis associated with hardy ornamental plants in the UK. Eur. J. Plant Pathol. 106:77-85.

10. Jeewon, R., Liew, E. C. Y., and Hyde, K. D. 2002. Phylogenetic relationships of Pestalotiopsis and allied genera inferred from ribosomal DNA sequences and morphological characters. Mol. Phylogen. Evol. 25:378-392.

11. Jeewon, R., Liew, E. C. Y., Simpson, J. A., Hodgkiss, I. J., and Hyde, K. D. 2003. Phylogenetic significance of morphological characters in the taxonomy of Pestalotiopsis species. Mol. Phylogen. Evol. 27:372-383.

12. Karakaya, A. 2001. First report of infection of kiwifruit by Pestalotiopsis sp. in Turkey. Plant Dis. 85:1028.

13. Kaushik, C. D., Thakur, D. P., and Chand, J. N. 1972. Parasitism and control of Pestalotia psidii causing cankerous disease of ripe guava fruits. Indian Phytopathol. 25:61-64.

14. Kwee, L. T., and Chong, K. K. 1990 Guava in
Malaysia: Production, Pests and Diseases. Tropical Press SDN. BHD, Kuala Lumpur, Malaysia.

15. Lin, C. C., Lai, C. S., and Tsai, S. F. 2003. Ecological survey of guava new fruit rot Phyllosticta rot (black spot) and other fruit rots. Plant Prot. Bull. 45:263-270.

16. McQuilken, M. P., and Hopkins, K. 2004. Biology and integrated control of Pestalotiopsis on container-grown ericaceous crops. Pest Manag. Sci. 60:135-142.

17. Metz, A. M., Haddad, A., Worapong, J., Long, D. M., Ford, E. J., Hess, W. M., and Strobel, G. A. 2000. Induction of the sexual stage of Pestalotiopsis microspora, a taxol-producing fungus. Microbiology 146:2079-2089.

18. Morton, J. 1987. Guava. Pages 356-363 in: Fruits of Warm Climates. Julia F. Morton, Miami, FL.

19. Nag Rag, T. R. 1993. Coelomycetous Anamorphs with Appendage-Bearing Conidia. Mycologue Publications, Waterloo, Ontario, Canada.

20. Pandey, R. R. 1990. Mycoflora associated with floral parts of guava (Psidium guajava L.). Acta Bot. Indica 18:59-63.

21. Patel, M. K., Kamat, M. N., and Hingorani, G. M. 1950. Pestalotia psidii Pat. on guava. Indian Phytopathol. 3:165-176.

22. Pirone, P. P. 1978. Diseases and Pests of Ornamental Plants. Wiley Interscience, New York

23. Raynor, R. W. 1970. A Mycological Colour Chart. Commonwealth Mycological Institute, Kew, Surrey, England.

24. Rivera, M. C., and Wright, E. R. 2000. First report of azalea petal blight caused by Pestalotiopsis guepini in Argentina. Plant Dis. 84:100.

25. Saitou, N., and Nei, M. 1987. The neighborjoining method: A new method for reconstructing phylogenetic trees. Mol. Biol. Evol. 4:406425 .

26. Sousa, M. F., Tavares, R. M., Geros, H., and Lino-Neto, T. 2004. First report of Hakea sericea leaf infection caused by Pestalotiopsis funerea in Portugal. Plant Pathol. 53:535.

27. Steyaert, R. L. 1953. New and old species of Pestalotiopsis. Trans. Br. Mycol. Soc. 36:8189.

28. Suto, Y., and Kobayashi, T. 1993. Taxonomic studies on the species of Pestalotiopsis, parasitic on conifers in Japan. Trans. Mycol.
Soc. Jpn. 34:323:344.

29. Sutton, B. C. 1980. The Coelomycetes: Fung Imperfecti with Pycnidia. Acervular and Stromata. Commonwealth Mycological Institute, Kew, Surrey, England

30. Tagne, A., and Mathur, S. B. 2001. First report of chlorotic spot of maize caused by Pestalotiopsis neglecta. Plant Pathol. 50:791.

31. Taguchi, Y., Watanabe, H., Akita, S., and Hyakumachi, M. 2001. Occurrence and control of ripe rot symptoms of persimmon fruit. Jpn. J. Phytopathol. 67:33-41.

32. Takeda, Y. 2002. Genetic analysis of tea gray blight resistance in tea plants. JARQ 36:143150 .

33. Takeda, Y. 2003. Phenotypes and genotypes related to tea gray blight disease resistance in the genetic resources of tea in Japan. JARQ 37:31-35

34. Thompson, J. D., Gibson, T. J., Plewniak, F., Jeanmougin, F., and Higgins, D. G. 1997. The ClustalX windows interface: Flexible strategies for multiple sequence alignment aided by quality analysis tools. Nucleic Acids Res. 24:4876-4882.

35. Trapero, A., Romero, M. A., Varo, R., and Sanchez, M. E. 2003. First report of Pestalotiopsis maculans causing necrotic leaf spots in nursery plants of Arbutus unedo and Ceratonia siliqua in Spain. Plant Dis. 87:1263.

36. Tuset, J. J., Hinarejos, C., and Mira, J. L. 1999. First report of leaf blight on sweet persimmon tree by Pestalotiopsis theae in Spain. Plant Dis. 83:1070.

37. White, R. P. 1930. Pathogenicity of Pestalotia spp. on rhododendron. Phytopathology 20:85 91.

38. White, T. J., Bruns, T., Lee, S., and Taylor, J. 1990. Amplification and direct sequencing of fungal ribosomal DNA genes for phylogenetics. Pages 315-321 in: PCR Protocols: A Guide to Methods and Applications. M. A. Innis, J. Gelfand, J. Sninky, and T. J. White, eds. Academic Press, San Diego, CA.

39. Yasuda, F., and Kobayashi, T. 1998. Occurrence of leaf spot of Japanese persimmon (Diospyros kaki) in Tottori Prefecture and its pathogenic fungi. (Abstr.) Ann. Phytopathol. Soc. Jpn. 64:433

40. Yasuda, F., Kobayashi, T., Watanabe, H., and Izawa, H. 2003. Addition of Pestalotiopsis spp. to leaf spot pathogens of Japanese persimmon. J. Gen. Plant Pathol. 69:29-32. 